\title{
The Caenorhabditis elegans CED-9 protein does not directly inhibit the caspase CED-3, in vitro nor in yeast
}

\author{
AM Jabbour ${ }^{1,2,3}$, P-k Ho ${ }^{1,2,3}$, MA Puryer ${ }^{1,2}$, DM Ashley ${ }^{1,2,3}$, \\ PG Ekert ${ }^{4,5}$ and CJ Hawkins ${ }^{\star, 1,2,3}$ \\ ${ }^{1}$ Murdoch Children's Research Institute, Parkville 3052, Australia \\ 2 Department of Haematology and Oncology, Children's Cancer Centre, Royal \\ Children's Hospital, Parkville 3052, Australia \\ 3 Department of Paediatrics, University of Melbourne, Parkville 3052, Australia \\ ${ }^{4}$ Department of Neonatology, Royal Children's Hospital, Parkville 3052, \\ Australia \\ 5 The Walter and Eliza Hall Institute, Royal Melbourne Hospital, Parkville 3050, \\ Australia \\ * Corresponding author: CJ Hawkins, Murdoch Children's Research Institute, \\ Royal Children's Hospital, Parkville 3052, Victoria, Australia. \\ Tel: + 6139345 5823; fax: 6139345 6524; \\ E-mail: chris.hawkins@mcri.edu.au
}

Received 21.1.04; revised 23.7.04; accepted 26.7.04

Edited by G Nunez

\begin{abstract}
A genetically defined pathway orchestrates the removal of 131 of the 1090 somatic cells generated during the development of the hermaphrodite nematode Caenorhabditis elegans. Regulation of apoptosis is highly evolutionarily conserved and the nematode cell death pathway is a valuable model for studying mammalian apoptotic pathways, the dysregulation of which can contribute to numerous diseases. The nematode caspase CED-3 is ultimately responsible for the destruction of worm cells in response to apoptotic signals, but it must first be activated by CED-4. CED- 9 inhibits programmed cell death and considerable data have demonstrated that CED-9 can directly bind and inhibit CED-4. However, it has been suggested that CED-9 may also directly inhibit CED-3. In this study, we used a yeast-based system and biochemical approaches to explore this second potential mechanism of action. While we confirmed the ability of CED-9 to inhibit CED-4, our data argue that CED-9 can not directly inhibit CED-3.

Cell Death and Differentiation (2004) 11, 1309-1316.

doi:10.1038/sj.cdd.4401501
\end{abstract}

Keywords: protease; apoptosis; nematode; worm; Bcl-2; Saccharomyces cerevisiae

Abbreviations: AFC, 7-amino-4-(trifluoromethyl)coumarin; Apaf-1, apoptotic protease activating factor-1; Bcl-2, B-cell lymphoma-2; GFP, green fluorescent protein; GST, glutathione$S$-transferase; PCR, polymerase chain reaction

\section{Introduction}

Cell fate decisions in the hermaphrodite nematode worm Caenorhabditis elegans are predetermined. During develop- ment, 131 particular cells (mostly neurons) die at predictable stages. ${ }^{1}$ The genes controlling this programmed cell death have been identified and cloned. The most downstream gene in the pathway encodes a cysteine aspartyl protease (caspase), CED-3. ${ }^{2,3}$ CED-3 shares similarities in sequence and enzymatic activity with a large family of caspases, including 10 human relatives (reviewed in Salvesen ${ }^{4}$ ). Like other caspases, the enzymatic activity of CED-3 can be suppressed in vitro and in vivo by the baculoviral pseudosubstrate caspase inhibitor, p35., ${ }^{5,6}$ Worms deficient in CED-3 possess an additional 131 cells, $^{7}$ resulting from the abnormal survival of those cells otherwise destined to die during embryogenesis. Likewise, these 131 cells also survive in nematodes bearing loss-of-function mutations in the ced-4 gene, ${ }^{7}$ which encodes a homolog of mammalian Apaf-1. Enforced expression of CED-4 triggers apoptosis that requires CED-3 activity, ${ }^{8}$ placing ced-4 genetically upstream of ced-3. Subsequent biochemical analyses demonstrated that CED-4 binds to CED-3, promoting its aggregation and activation. ${ }^{9-13}$

The majority of nematode cells are protected from developmental death by CED-9. ${ }^{14}$ CED-9 exhibits limited but significant homology to the mammalian apoptosis inhibitor Bcl-2, ${ }^{15}$ which can also inhibit nematode cell death. ${ }^{15,16}$ Conclusive evidence indicates that CED-9 can exert a prosurvival effect through direct interaction with and inhibition of CED-4. ${ }^{9,10,17,18}$ However, it has also been suggested by Xue and Horvitz ${ }^{19}$ that CED-9 may habor a second antiapoptotic activity. CED-9 can be proteolytically processed by CED- $3^{19}$ raising the possibility that it could directly inhibit CED-3 via a p35-like pseudo-substrate mechanism. It was not possible to test whether CED-9 could inhibit CED-3 in the absence of CED-4 in worm cells, so Xue and Horvitz ${ }^{19}$ were denied the opportunity to directly test their hypothesis that CED-3 can inhibit CED-9, using their worm-based system. Uncleavable mutants of CED-9 had reduced antiapoptotic potential in transgenic worm experiments ${ }^{19}$ providing circumstantial evidence for the theory that CED-9 possesses a CED-3 inhibitory activity.

The C. elegans programmed cell death pathway is a valuable model for apoptosis pathways of other organisms, including mammals. As such, it is important that the mechanisms of action of the principal components of this pathway are fully elucidated. Although the ability of CED-9 to inhibit CED-4 has been firmly established, data verifying or refuting the proposed CED-3 inhibitory activity of CED-9 has not been published to date. This study employed a yeast-based system and biochemical analyses to investigate whether CED-9 could directly inhibit CED-3 in a manner similar to p35. Although the results of this study confirm the ability of CED-9 to inhibit CED-4, our data argue that CED-9 cannot directly suppress CED-3 activity. 


\section{Results}

\section{Active CED-3 kills Saccharomyces cerevisiae}

Heterologous expression of active caspases can be lethal to the yeast $S$. cerevisiae. ${ }^{20-23}$ For a caspase to be lethal to yeast, it must be present at sufficient levels, adopt an active conformation and its substrate specificity must permit it to cleave proteins required for yeast survival. Caspases that do not spontaneously autoactivate can be activated by coexpression of their physiological adaptors, for example Apaf-1 can activate caspase- 9 in yeast. ${ }^{24}$

When expressed from the galactose inducible Gal1/10 promoter ( $p$ GALL), CED-3 caused a low but significant level of yeast cell death (Figure 1, column 2), compared to yeast transformed with empty vectors (column 1). When CED-3 was expressed with two CED-3 expression plasmids using different nutritional selections, a dramatic increase in cell

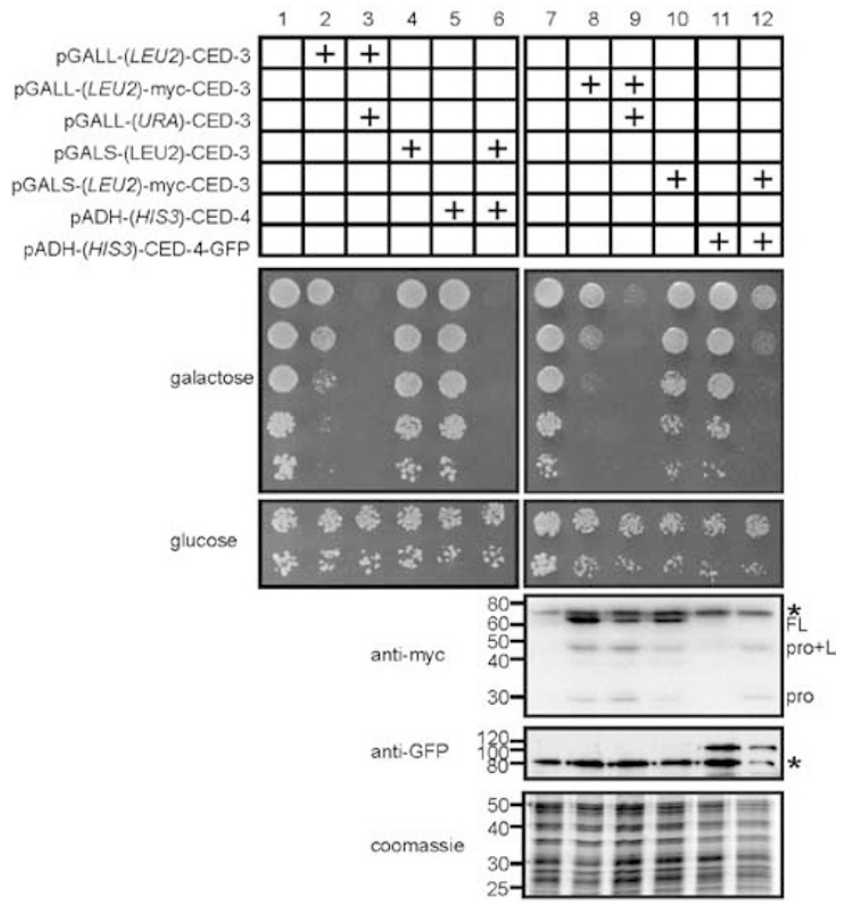

Figure 1 Killing S. cerevisiae by enforcing expression of CED-3 and CED-4. A semiquantitative assay compares the effect of transgenes on yeast growth and viability. Yeast cells were transformed with the indicated plasmids. Suspensions of each transformant were prepared at standardized concentrations. Serial dilutions were made and spotted onto solid inducing media (galactose) or repressing media (glucose) vertically down the plate. Colony size indicates growth rate and colony number cell viability. CED-3 was expressed either from a high level galactose-inducible promoter (pGALL) or from a truncated promoter, directing lower level expression (pGALS). To further manipulate expression levels, either one plasmid or two plasmids under different nutritional selections were transformed. The impact of fusion of epitope tags to CED-3 and CED-4 was assessed (right panels). Immunoblotting was performed to visualize expression and processing of the epitope-tagged CED-3. The degree of processing of CED3 is reflected by the proportion of full-length myc-CED-3 (FL) compared to partially processed and completely processed myc-CED-3 (pro $+\mathrm{L}$ and pro, respectively). An asterisk denotes an endogenous protein recognized by the antimyc antibody, which migrates slightly slower than full length myc-CED-3. Immunoblotting was also used to detect epitope-tagged CED-4. An asterisk denotes a yeast protein recognized by the anti-GFP antibody, migrating slightly faster than CED-4-GFP. Protein loading was monitored by Coomassie staining death resulted (column 3), presumably because sufficient CED-3 was expressed for its autoactivation. In contrast, yeast expressing CED-3 at a lower level under the control of a crippled Gal1/10 promoter (pGALS) survived (column 4). CED-4 alone was not toxic to yeast (column 5), but yeast bearing the CED-4 plasmid together with the sublethal CED-3 construct died on inducing medium (column 6), suggesting that CED-4 could activate CED-3 in yeast. To visualize CED-3 and CED-4 expression in yeast, epitope tagged proteins were expressed, and detected by immunoblotting (Figure 1, right panels). CED-4 fused to green fluorescent protein (GFP) and myc-tagged CED-3 could cooperate to kill yeast (column 12), although the toxicity was slightly less marked than that triggered by coexpression of the untagged proteins (compare columns 6 and 12).

At least two alternative explanations could account for the yeast lethality resulting from coexpression of CED-3 and CED4. The toxicity could either be additive (perhaps resulting from coexpression of two independent mildly lethal proteins) and/or synergistic (due to activation of CED-3 by CED-4). To differentiate between these possibilities, processing of tagged CED-3 was examined by anti-myc immunoblotting (Figure 1) and quantitated as described in the Materials and Methods. Most of the CED-3 protein (73\%) in lysates from yeast transformed with the low level tagged CED-3 plasmid (lane 10) was full-length. Coexpression of CED-4 enhanced CED-3 processing: only $30 \%$ of CED-3 in lysates from a cotransformant (lane 12) was full-length. This implies that CED-4mediated activation of CED-3 contributes to the lethality resulting from coexpression of CED-4 with low levels of CED-3.

\section{CED-9 inhibits CED-4-dependent yeast death but does not affect lethality resulting from CED-3 autoactivation}

The data presented in Figure 1 indicated that yeast could be killed in a manner either solely dependent on CED-3, or requiring both CED-3 and CED-4. We exploited this finding to explore the capacity of CED-9 to inhibit CED-4 and/or CED-3. Consistent with abundant evidence from nematode, mammalian cell culture and biochemical experiments (cited above), CED-9 greatly reduced the death of yeast provoked by the coexpression of CED-4 with low levels of CED-3 (Figure 2, compare column 2 with column 3). FLAG-tagged CED-9 had a similar effect (column 4). Coexpression of either untagged or FLAG-tagged CED-9 also decreased the proportion of CED-3 processed by CED-4 (47 or $48 \%$ respectively, compared to $79 \%$ for the CED-3/CED-4 transformant). The broad spectrum baculoviral caspase inhibitor p35 also conferred protection (column 5), as expected given the ability of p35 to inhibit CED3 in transgenic worms and in vitro. ${ }^{5,6}$ p35 also reduced CED-3 processing (52\% processed).

To test whether CED-9 could also directly inhibit CED-3, we transformed yeast bearing the high-level CED-3 expression plasmid with plasmids encoding untagged or tagged CED-9. Empty vector and a p35 plasmid were used as controls. Yeast transformed with pGALL-CED-3 were killed upon induction of the caspase (Figure 2, column 7). This lethality was completely suppressed by p35 (column 10). In contrast to its 


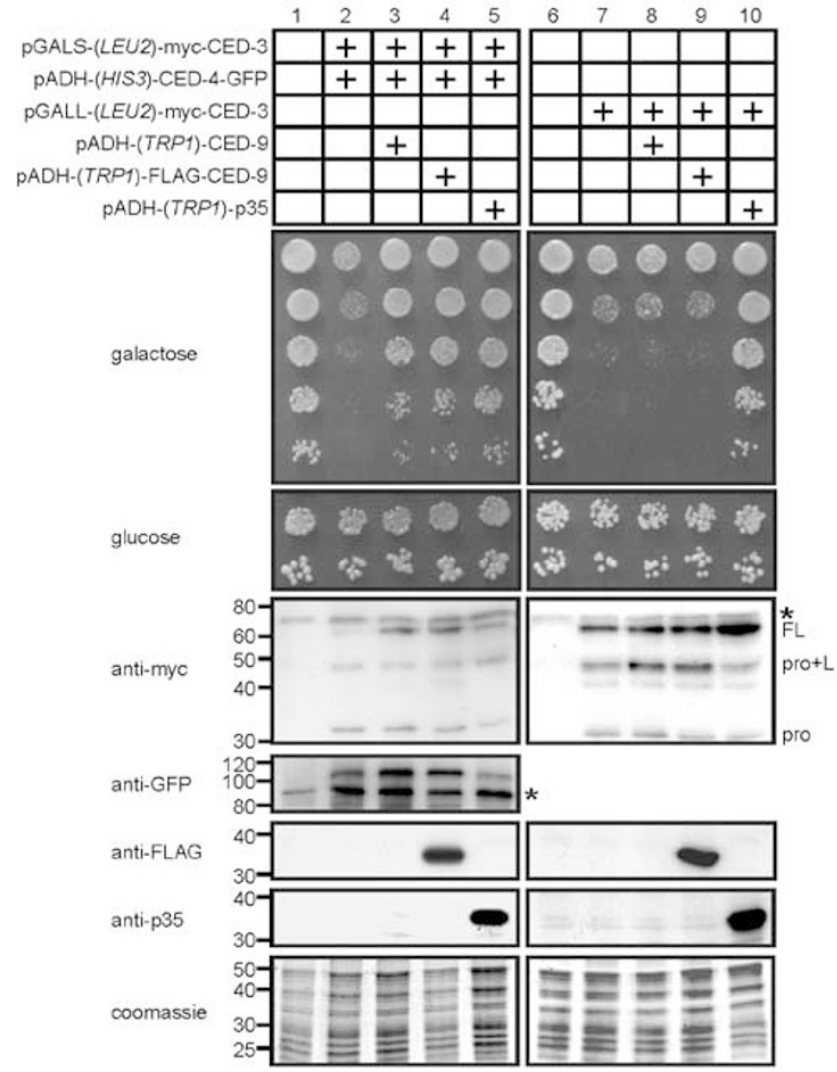

Figure 2 CED-9 inhibits CED-4-dependent yeast death but not lethality due to CED-3 autoactivation. Yeast transformed with the indicated plasmids were spotted onto inducing and repressing medium as detailed in Figure 1. A FLAGtagged CED-9 construct was used to visualize CED-9 expression. The impact of coexpression of CED-9 or p35 on processing of myc-CED-3 was monitored by anti-myc immunoblotting, as described in Figure 1. Expression of GFP-tagged CED-4, FLAG-tagged CED-9 and p35 were verified by immunoblotting. Asterisks indicate endogenous proteins detected by the anti-GFP and anti-myc antibodies. Coomassie staining indicates loading

efficient inhibition of CED-4-dependent death, neither tagged nor untagged CED-9 afforded any protection against yeast death induced by overexpression of CED-3 (columns 8 and 9). CED-9 also had no effect on CED-3 autoprocessing. In total, $55 \%$ of CED-3 was processed in yeast cotransformed with pGALL-(LEU2)-CED-3 and empty vector, compared to $50 \%$ in yeast coexpressing CED-3 together with untagged CED-9 (or $59 \%$ for FLAG-CED-9). However, coexpression of p35 did suppress CED-3 autocleavage (25\% processed). Expression of FLAG-CED-9 and p35 was verified by immunoblotting.

\section{Purified CED-9 does not inhibit the substrate cleavage activity of recombinant CED-3}

The results presented above indicate that CED-9 is incapable of directly inhibiting CED-3, even though it can function in yeast, as demonstrated by its ability to inhibit CED-4dependent yeast death. This argues against the possibility that in these assays yeast proteins were somehow inactivating CED-9. To completely preclude any possibility that the inability of CED-9 to inhibit CED-3 was due to interference from yeast proteins, a biochemical analysis was performed using purified proteins. Recombinant CED-3 was generated, and its ability to cleave the synthetic fluorogenic substrate AcDEVD-AFC was assayed in the presence and absence of CED-9. We, like others, ${ }^{25}$ were unable to produce full-length CED-9 from bacteria with sufficient purity for biochemical characterization. A truncation mutant lacking the hydrophobic carboxyl terminal domain was therefore used. To confirm that this deletion did not affect stability or activity of the protein, a FLAG-tagged deletion mutant was tested in the yeast death assays and its expression verified by immunoblotting. As for full-length CED-9, the deletion mutant (CED-9 ${ }^{1-251}$ ) could inhibit CED-4-dependent yeast death but not death triggered by autoactivated CED-3 (Figure 3a). Bacterially generated, purified CED-3 required its active site cysteine to cleave the synthetic substrate Ac-DEVD-AFC, as an active site mutant (CED-3 ${ }^{\mathrm{C} 358 \mathrm{~S}}$ ) was inactive in this assay (data not shown). p35 significantly reduced the substrate-cleavage activity of recombinant CED-3 (Figure 3b). Like the negative control, glutathione-S-transferase (GST), CED-9 and a cleavage site mutant of p35 were ineffectual in this assay (Figure $3 b$ ). CED9 was unable to inhibit CED-3, regardless of whether the substrate was present at 250-fold excess relative to CED-9, or at equimolar concentration.

\section{Analysis of the cleavage by CED-3 of CED-9}

To determine the significance of cleavage of CED- 9 by CED3 , we mutated the previously identified cleavage site aspartates DAQD ${ }^{47}$ and ESID ${ }^{67}$. Wild-type CED-9 and cleavage site mutants were in vitro translated in the presence of ${ }^{35} \mathrm{~S}$-methionine and incubated with various amounts of CED-3 or caspase-3. In vitro translated p35 was used as a control (Figure 4a). Both caspase-3 and CED-3 cleaved CED9 (Figure 4b). Replacing the cleavage site DAQD ${ }^{47}$ with a consensus Caspase- 3 cleavage site (DEVD ${ }^{47}$ ) increased the ability of both Caspase-3 and CED-3 to cleave CED-9 (Figure 4c). In contrast, replacing both proposed $\mathrm{P} 1$ aspartate residues with alanines prevented cleavage of CED- 9 by CED3 or caspase-3 (Figure $4 d$ ).

The ability of CED-9 to be cleaved by CED-3 may be important for its function in inhibiting nematode programmed cell death. ${ }^{19}$ To explore this possibility, we tested the abilities of FLAG-tagged CED-9 cleavage site mutants to inhibit CED4-dependent yeast death. Mutations in CED-9 that either enhanced or abolished its ability to be cleaved by CED-3 did not affect the ability of CED-9 to inhibit CED-4-dependent yeast death (Figure 5, compare column 3 with columns 4 and 5). Like wild-type CED-9, the mutants were unable to inhibit yeast death induced by CED-3 autoactivation (Figure 5 , columns 10-12). The product of CED-3 cleavage of CED-9 (CED-9 ${ }^{68-280}$ ) resembles Bcl-2 more closely than does fulllength CED-9. It has been previously reported that a truncation protein engineered to mimic this cleavage product protected mammalian cells from apoptosis more efficiently than wild-type CED-9. ${ }^{26}$ When expressed in yeast, this truncation mutant was functionally indistinguishable from the wild type CED-9 protein, inhibiting yeast death triggered by coexpression of CED-3 and CED-4 but not by CED-3 autoactivation (Figure 5, compare columns 6 and 13). 
a

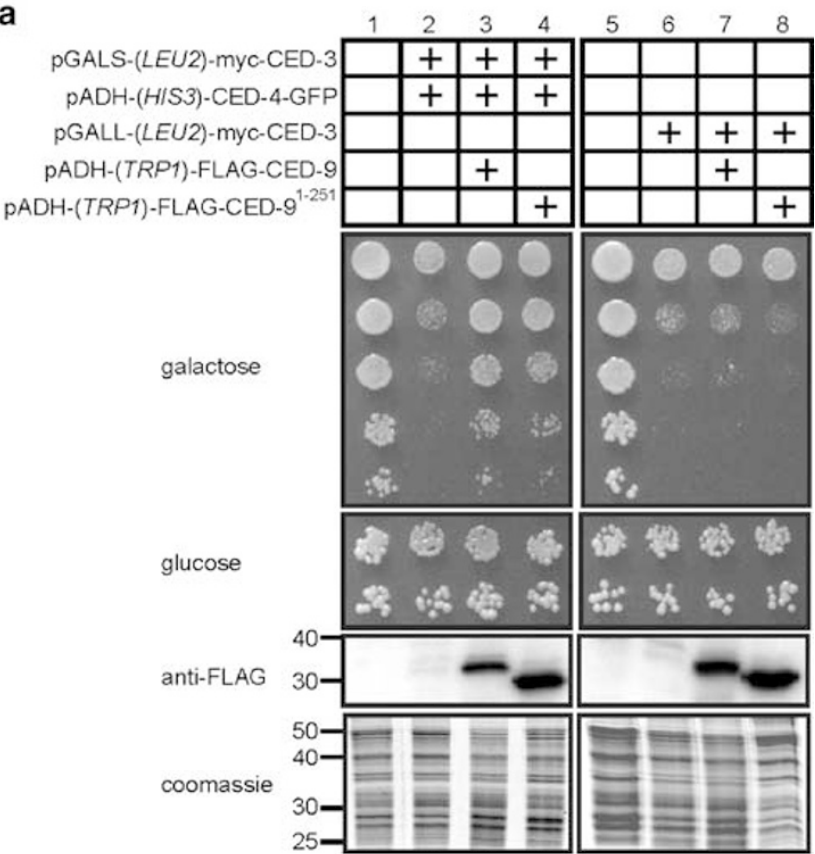

b

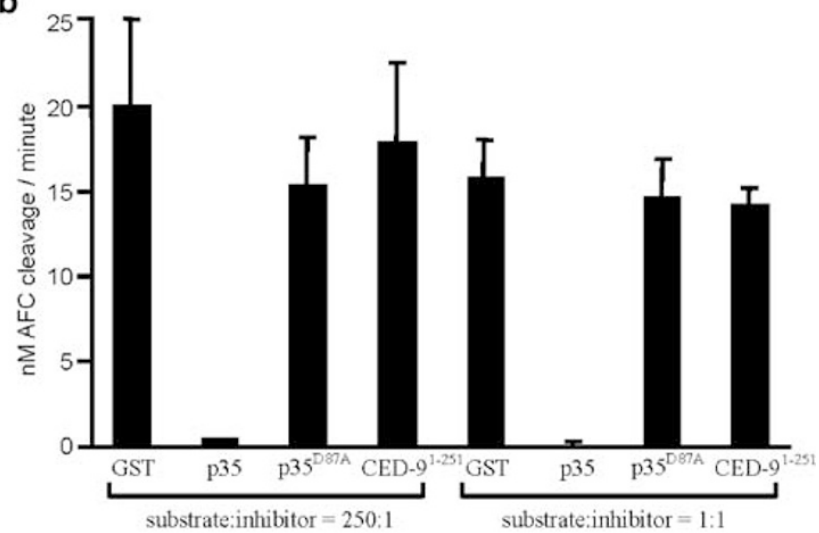

Figure 3 Purified CED-9 does not inhibit the enzymatic activity of recombinant CED-3. (a) Yeast transformed with the indicated plasmids were spotted onto inducing and repressing medium as detailed in Figure 1. Expression of FLAGCED-9 and FLAG-CED-9 ${ }^{1-251}$ were verified by immunoblotting. Coomassie staining indicates loading. (b) Recombinant CED-3 was incubated with the indicated purified proteins and the caspase substrate Ac-DEVD-AFC. The substrate was used at either a 250-fold molar excess over CED-9 or control proteins, or at equimolar concentration. Substrate cleavage was measured fluorometrically; the maximal rate of cleavage is shown

Approximately equivalent expression of FLAG-tagged wildtype and mutant CED-9 proteins was verified by immunoblotting (Figure 5). These results imply that the amino terminal portion of CED-9 is dispensable for inhibition of the core nematode cell death pathway.

\section{Discussion}

The pathway controlling nematode developmental programmed cell death was previously genetically elucidated.

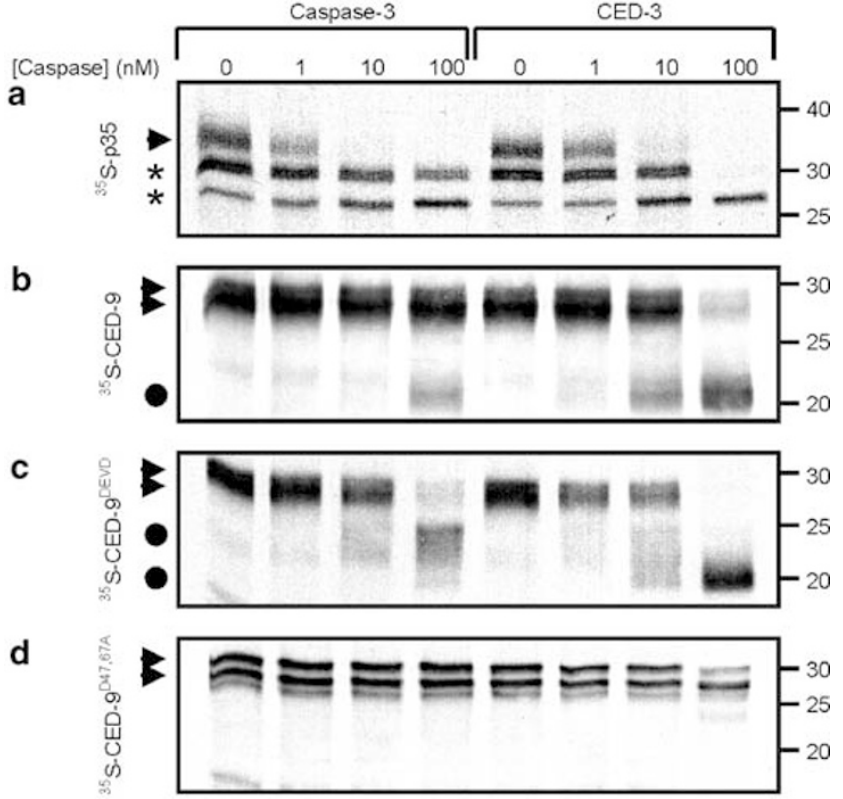

Figure 4 Caspase cleavage of wild-type CED-9 and CED-9 mutants. The indicated ${ }^{35} \mathrm{~S}$-labeled in vitro translated proteins were incubated with the stated concentrations of caspase-3 or CED-3 for $90 \mathrm{~min}$. The cleavage was visualized by SDS-PAGE and autoradiography. Arrows denote full-length proteins, asterisks indicate nonspecific bands and circles show cleavage products

Molecular biology and biochemistry were subsequently used to define the intermolecular relationships of the various pathway components. This pathway, which represents an important model for describing mammalian apoptotic signal transduction, is now generally well understood. However, two mechanisms have been proposed to explain the prosurvival function of CED-9. Inhibition of CED-4 has been firmly demonstrated, but direct inhibition of CED-3 has also been suggested. CED-9 is a homolog of the mammalian antiapoptotic protein $\mathrm{Bcl}-2$, whose mechanism of action is still hotly debated. It was important, therefore, to experimentally test the second potential mechanism of action (that of direct CED-3 inhibition by CED-9). By manipulating expression levels of CED-3, we have developed a system in which yeast death can be induced by CED-3 autoactivation, or dependent on CED-4mediated activation of CED-3. CED-9 could inhibit yeast death resulting from CED-4 activation of CED-3, but could not block lethality due to CED-3 autoactivation. Verification of the inability of CED-9 to directly inhibit CED-3 was obtained using a fluorometric assay in which cleavage of a substrate by CED3 was assayed in the presence or absence of CED-9. Unlike p35, CED-9 could not suppress CED-3 cleavage of the fluorogenic substrate Ac-DEVD-AFC (present at 250-fold excess over CED-9), implying that CED-9 is not suicide substrate inhibitor of CED-3. Even when the substrate was present at the same concentration as CED-9, CED-9 had no effect in the fluorometric assay, arguing against a competitive inhibition function. Together, these data refute the proposition that CED-9 can directly inhibit CED-3.

Biochemical analyses confirmed the earlier demonstration ${ }^{19}$ that CED-3 could cleave CED-9. (No cleavage of CED-9 


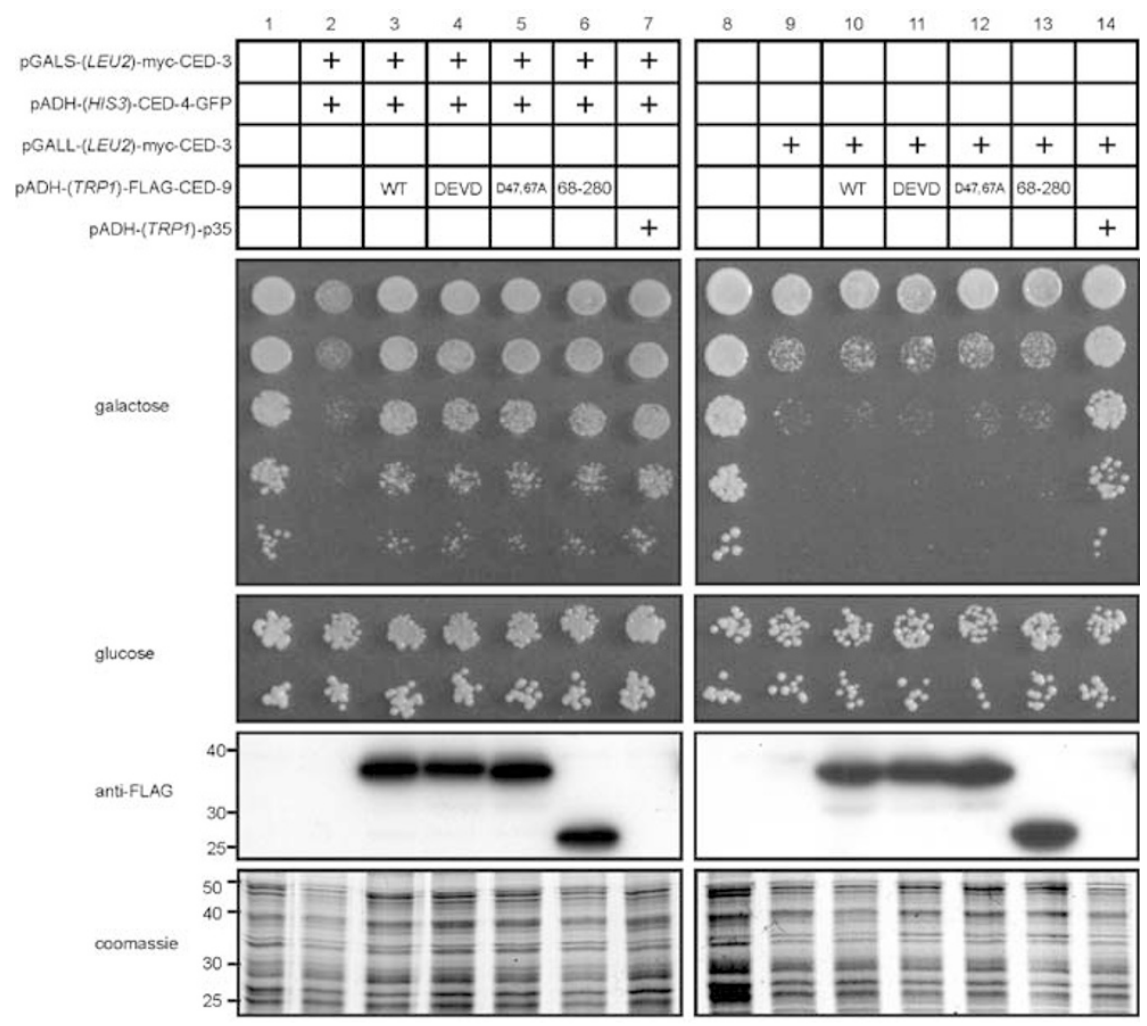

Figure 5 Altering the susceptibility of CED-9 to caspase cleavage does not affect its ability to inhibit CED-4-dependent yeast death. Yeast transformed with the indicated plasmids were spotted onto inducing and repressing medium as detailed in Figure 1. Expression of either wild-type FLAG-CED-9 or the indicated mutants was monitored by anti-FLAG immunoblotting. Coomassie staining illustrates loading

by CED-3 was detected in yeast lysates, presumably because CED-3 levels in yeast were much lower, relative to CED-9, than those used in vitro.) Both an uncleavable mutant and a truncation mutant designed to recapitulate the CED-3 cleavage product of CED-9 (CED-9 ${ }^{68-280}$ ) were able to inhibit CED-4 activity (but not CED-3 activity) efficiently in yeast. Although these mutants were previously reported to exhibit protective activity in worms, they were significantly less potent suppressors of programmed cell death than wild-type CED-9; the cleavage site mutant rescued around a third as many cells as wild-type CED-9 and the truncation mutant rescued around half. ${ }^{19}$ If CED-9 cannot inhibit CED-3, as suggested by our data, why would mutations affecting the ability of CED-3 to cleave CED-9 affect CED-9's prosurvival capacity in nematode cells? It is possible that these cleavage site mutations diminish the functional interaction between CED-9 and CED-4 in nematode cells, but that this reduction is too subtle to be detected using the yeast system. Alternatively, residues $D^{47}$ and $D^{67}$ may be required for maximal stability of the CED-9 protein, such that mutation of these residues or their removal by an amino-terminal deletion may lead to a degree of protein instability in nematode cells, but not in yeast.

In summary, we have used yeast-based and biochemical assays to explore two proposed mechanisms of action of the nematode-programmed cell death inhibitor, CED-9. Our data confirm the ability of CED-9 to inhibit CED-4, but are not consistent with direct inhibition of CED-3 by CED-9.

\section{Materials and Methods}

\section{Plasmids}

Yeast expression constructs

Yeast expression plasmids based on the pRS31X series $^{27}$ directed expression of the various transgenes from the Adh promoter (pADH) or either an intact (pGALL) or truncated (pGALS) Gal 1/10 promoter. The following constructs have been previously described: $\mathrm{pADH}-(T R P 1){ }^{28}$ pGALL-(LEU2) and pGALS-(LEU2), ${ }^{20}$ pADH-(TRP1)-p35 ${ }^{22}$ and pGALL(URA). ${ }^{24}$ The HIS3 gene containing Pvul fragment of $\mathrm{pRS} 313^{27}$ was ligated to the Pvul fragment of $\mathrm{pADH}-(T R P 1)$, which contained the promoter, polylinker and terminator, ${ }^{28}$ yielding pADH-(HIS3). The CED-4coding sequence was amplified with primers 1 and 2. A portion of the product was cut with EcoRI, BamHI and Notl. The EcoRl/Notl fragment, encoding the carboxyl-terminal half of CED-4, was ligated into pADH(HIS3) cut with EcoRI and Notl, to give pADH-(HIS3)-CED-4C. Another portion of the PCR product was cut with EcoRI and Ndel and the EcoRl/ $E c o R I$ fragment, encoding the amino-terminal half of CED-4, was then ligated into $\mathrm{pADH}-(\mathrm{HIS3})-\mathrm{CED}-4 \mathrm{C}$ cut with $\mathrm{EcOR}$ and treated with alkaline phosphatase, yielding pADH-(HIS3)-CED-4 (PCR was used to determine insert orientation). To make pADH-(HIS3)-CED-4-GFP, GFP ${ }^{\text {S65 T }}$ was amplified from p416-MET25-GFP ${ }^{\text {S65 T }}$ (a kind gift from Trevor Lithgow) with primers 3 and 4 and cut with Notl and Xhol and cloned into pADH(HIS3)-CED-4 cut with Notl and Sall. To remove the stop codon of CED-4 to produce $\mathrm{pADH}-(\mathrm{HIS} 3)-\mathrm{CED}-4-\mathrm{GFP}$, the $\mathrm{Xbal} / \mathrm{Notl}$ fragment was replaced with a fragment amplified with primers 5 and 6 and cut with 
$X$ bal and Notl. The coding region of CED-3 was amplified with primers 7 and 8 and the product cut with $B a m H I$ and $X b a l$ and cloned into pGALL(LEU2) cut with BamHI and Xbal to produce pGALL-(LEU2)-CED-3. CED3-coding sequence was excised from pGALL-(LEU2)-CED-3 with BamHI and $X$ bal and inserted both into pGALS-(LEU2) cut with BamHI and Xbal to make pGALS-(LEU2)-CED-3 and into pGALL-(URA) cut with BamHI and $X$ bal to generate $P G A L L-(U R A)-C E D-3$. To express myc-tagged CED3 , the coding region of CED-3 was amplified with primers 9 and 10 , cut with $B a m H I, X$ Xhol and Notl, and the 720 base pair fragment was ligated into pGALL-(LEU2)-CED-3 cut with BamHI and Xhol, yielding pGALL-(LEU2)myc-CED-3. The BamHI/Xbal fragment was then ligated into pGALS(LEU2) to give pGALS-(LEU2)-myc-CED-3. The CED-9 coding sequence was amplified with primers 11 and 12, cut with EcoRI and Notl and ligated into pADH-(TRP1) cut with EcoRI and Notl to make pADH-(TRP1)-CED-9. pADH-(TRP1)-FLAG-CED-9 was made by amplifying CED-9 with primers 13 and 14, cutting with EcoRI and Notl and ligating into pADH-(TRP1). pADH-(TRP1)-CED-9 ${ }^{1-251}$ was generated by amplifying CED-9 ${ }^{1-251}$ with primers 15 and 16 , cutting the product with EcoRI and Notl and ligating it into $\mathrm{pADH}-(T R P 1)$ cut with EcoRI and Notl. pADH-(TRP1)FLAG-CED- ${ }^{1-251}$ was made by replacing the Pstl fragment of $\mathrm{pADH}$ (TRP1)-FLAG-CED-9, encoding the carboxyl portion of the protein, with the Pstl fragment from pADH-(TRP1)-CED-9 ${ }^{1-251}$. To generate $\mathrm{pADH}$ (TRP1)-CED-9 ${ }^{\text {D47,67A }}$, DNA encoding the amino terminus of CED-9 was amplified from $\mathrm{PADH}-($ TRP1)-CED-9 with primers 13 and 17 and cut with EcoRl and Hindll. DNA encoding the carboxyl terminal part of CED-9 was amplified with primers 18 and 14, cut with Hindll and Notl and inserted into a Bluescript vector (modified such that its polylinker bore EcoRI, Hindll and Notl sites in that order and lacked a Clal site), as a three-way ligation, yielding pBluescript-FLAG-CED-9N + C. Oligonucleotides 19 and 20 were annealed together, then ligated into pBluescript-FLAG-CED-9N $+\mathrm{C}$ cut with Hindlll and Clal to produce pBluescript-FLAG-CED-9 ${ }^{\text {D47,67A }}$. The EcoRI/Notl fragment encoding the mutated FLAG-CED-9 was then excised and ligated into pADH-(TRP) to give pADH-(TRP1)-FLAGCED-9 $9^{\mathrm{D} 47,67 \mathrm{~A}}$. To make pADH-(TRP1)-CED-9 ${ }^{\mathrm{DEVD}}$, DNA encoding the amino-terminal portion of CED-9 was amplified with oligonucleotides 13 and 21 and the product was cut with EcoRl and Bgll. DNA encoding the carboxyl-terminal portion of CED-9 was amplified the primers 22 and 14 and the product was cut with Bgll and Notl. The two fragments were inserted into $\mathrm{PADH}-(T R P 1)$ as a three-way ligation to give pADH-(TRP1)-FLAG-CED-9 ${ }^{\mathrm{DEVD}}$. CED- $9^{68-280}$ was amplified with primers 23 and 14, the product cut with EcoRI and Notl and ligated into pADH-(TRP1) cut with EcoRI and Notl, to give pADH-(TRP1)-FLAGCED-9 $9^{68-280}$

\section{Bacterial expression constructs}

CED-3 was amplified with primers 24 and 25 and the product cut with $\mathrm{Ndel}$ and Notl, giving two fragments. The $5^{\prime} \mathrm{Ndel} / \mathrm{Notl}$ fragment was cloned into pET23a (Invitrogen) to produce pET23a-CED-3N. pET23a-CED-3N was then cut with Notl and alkaline phosphatase treated and the $5^{\prime}$ Notl/Notl fragment was then cloned into it to give pET23a-CED-3. To produce enzymatically inactive recombinant CED-3, DNA encoding a mutated amino terminal fragment of CED-3 was amplified using primers 24 and 26 and the product cut with Ndel and Sall, then ligated into pET23a-CED-3 cut with Ndel and Sall, to give pET23a-CED-3 ${ }^{\mathrm{C} 385 \mathrm{~S}}$. DNA encoding residues 1-251 inclusive of Ced-9 was amplified with primers 27 and 28, cut with Ndel and Xhol and cloned into pET23a cut with Ndel and Xhol to produce $\mathrm{pET} 23 \mathrm{a}-\mathrm{CED}-9^{1-251}$. The coding region of $\mathrm{p35}$, lacking the stop codon, was amplified with primers 29 and 30 and cloned into pET23a cut with Ndel and Xhol to give pET23a-p35.
Constructs for in vitro transcription/translation CED-9 was cut out of pADH-(TRP)-CED-9 with EcoRI and Notl and ligated into pBluescript II SK + (Stratagene) cut with EcoRI and Notl, yielding pBluescript-CED-9. CED-9 ${ }^{\text {D47, 67A }}$ was cut out of pADH-(TRP)-CED-9 ${ }^{\text {D47, }}$ $67 \mathrm{~A}$ with EcoRI and Notl and ligated into pBluescript II SK + cut with EcoRI and Notl to generate pBluescript-CED-9 $9^{\mathrm{D} 47,67 \mathrm{~A}}$. CED-9 ${ }^{\mathrm{DEVD}}$ was cut out of pADH-(TRP)-CED-9 ${ }^{\mathrm{DEVD}}$ with EcoRI and Notl and ligated into pBluescript II SK + cut with EcoRI and Notl, yielding pBluescript-CED-9 ${ }^{\mathrm{DEVD}}$. p35 was amplified with primers 31 and 32 , cut with $\mathrm{BamHI}$ and $\mathrm{Xbal}$ and cloned into pBluescript II SK + to produce pBluescript-p35.

All PCR-derived stretches of DNA were sequenced to verify the presence of intended mutations and the absence of unintended ones.

Oligonucleotides

1: GTGAATTCATGCTCTGCGAAATCGAATGC

2: GAGCGGCCGCTTAACAGCATGCAAAATTTTTGAGGG

3: GAATGCGGCCGCAATGGGTAAAGGAGAAGAACTTTTC

4: CCGCTCGAGTTATTTGTATAGTTCATCCATGCCATG

5: TACGGATATTTTGCTGATGC

6: GAATGCGGCCGCACAGCATGCAAAATTTTTGAGGGAGTC

7: CG GGATCC ATGATGCGTCAAGATAGAAGGAGCTTGC

8: $\quad$ GCTCTAGATTAGACGGCAGAGTTTCGTGCTTCCGGCC

9: GCGGATCCATGGAGCAGAAATTAATCAGCGAAGAGGACCTCAGATCTATGATGCGTCAAGATAGAAGG

10: CTTTATTATTTTTATTTTTATTGAGAGGGTGG

11: GGAATTCATGACACGCTGCACGGCGGACAAC

12: GAGCGGCCGCTCTAGATTACTTCAAGCTGAACATCATC

13: GCGAATTCATGGACTACAAGGACGACGATGACAAGATGACACGCTGCACGGCGGAC

14: GAGTCACTTTAAAATTTGTATACAC

15: GTTTCCTCGTCATTGTTCTCGTTCCC

16: GAATGCGGCCGCTCACCGTCTGTTCTGCTTCCGGCGTC

17: CGGTGATGGCAAAGCTTGAGCATC

18: GCGAATTCAGAAAGCTTCGGAGAATCGATTGCTGGAAAAATCAATGAT

19: AGCTTTGCCATCACCGAGTAGGCAGGCTTCGACGCGAAGAATGTCCATCGGAGAAT

20: CGATTCTCCGATGGACATTCTTCGCGTCGAAGCCTGCCTACTCGGTGATGGCAA

21: GATGGCAGATCTACCTCATCACTATTGATTCCAAAATCGGTG

22: ATGCTCAAGATCTGCCATCACCGAGTAGGCAGGCTTC

23: GCGAATTCATGGACTACAAGGACGACGATGACAAGATGGGAAAAATCAATGATTGGGAAG

24: GGAATTCCATATGATGCGTCAAGATAGAAGG

25: GAATGCGGCCGCGACGGCAGAGTTTCGTGCTTC

26: GCGCGCTCGACAGAATCCAAGACTGGGAATCCATTGTCACGACGTTCGCCTCGACTAGCCTGC

27: GGAATTCCATATGACACGCTGCACGGCGGAC

28: GAATGCGGCCGCCCGTCTGTTCTGCTTCCGGCGTC

29: GGAATTCCATATGTGTGTAATTTTTCCGGTAG

30: CCCTCGAGTTTAATTGTGTTTAATATTAC

31: GCGGATCCGCCATGTGTGTAATTTTTCCGGTAG

32: GCTCTAGAGCGGCCGCTTATTTAATTGTGTTTAATATTAC

\section{Yeast transformation and death assays}

The $S$. cerevisiae yeast stain W303 $\alpha$ was transformed and analyzed in survival assays as previously described. ${ }^{23}$ Briefly, single transformants bearing each desired combination of expression plasmids or empty vectors were grown until stationary phase in selective repressing medium. After washing three times in Tris $\mathrm{HCl} 10 \mathrm{mM} \mathrm{pH} 8$, EDTA $1 \mathrm{mM}, 5 \mu \mathrm{l}$ of 
serial five-fold dilutions of each transformant suspension (from $\mathrm{OD}_{550}=0.086$ ) were spotted onto inducing and repressing selective minimal media plates.

\section{Immunoblotting}

Transformants were grown and expression induced as previously described. ${ }^{22}$ Immunoblotting was performed as previously reported. ${ }^{22}$ Lysates were also run on gels and stained with Coomassie brilliant blue (BioRad) to visualize protein loading. The antibodies used in this study were anti-GFP (a kind gift from Trevor Lithgow and Lena Burri), anti-p35 (BD Biosciences), anti-myc (clone 9B11; Cell Signaling), anti-FLAG (clone M2; Sigma), anti-rabbit-HRP (Amersham) and anti-mouse-HRP (Sigma). Enhanced chemoluminescence (ECL) anti-myc signals were quantitated using a Chemi-doc apparatus (BioRad). Processing of myc-CED-3 was calculated by adding the specific ECL signals corresponding to partially and fully processed bands and expressing that as a percentage of the total myc-CED-3 signal in each lane.

\section{Generation of recombinant proteins}

The pET23a constructs described above were introduced into BL21(DE3)LysS bacteria (Novagen). Transformants were grown overnight at $37^{\circ} \mathrm{C}$, then the cultures were expanded $1: 5$ into fresh medium including IPTG $(1 \mathrm{mM})$ and grown at $30^{\circ} \mathrm{C}$ for a further $4 \mathrm{~h}(6 \mathrm{~h}$ for CED-9). The bacteria were harvested and lysed by freeze-thawing then resuspended in binding buffer ( $50 \mathrm{mM} \mathrm{NaH}_{2} \mathrm{PO}_{4}, 300 \mathrm{mM} \mathrm{NaCl}$ ) with $5 \mu \mathrm{M}$ imidazole and sonicated. The sonicate was bound to NiNTA resin (Qiagen), then the resin was washed and the His-tagged proteins eluted with binding buffer containing $250 \mu \mathrm{M}$ imidazole.

\section{Fluorogenic CED-3 activity assays}

The cleavage of Ac-DEVD-AFC by CED-3 (10 nM) was measured fluorometrically in the presence of GST, p35, p35 ${ }^{\mathrm{D} 87 \mathrm{~A}}$ or CED- $9^{1-251}$. To achieve a substrate : inhibitor ratio of $250: 1,50 \mu \mathrm{M}$ Ac-DEVD-AFC and $200 \mathrm{nM}$ recombinant proteins were used. For equal molar ratios of substrate and inhibitor, $5 \mu \mathrm{M}$ Ac-DEVD-AFC and $5 \mu \mathrm{M}$ recombinant proteins were used. The maximal cleavage rate was used to quantitate caspase activity, expressed as the change in concentration of free AFC per minute.

\section{Caspase cleavage of in vitro translated substrates}

${ }^{35}$ S-labeled proteins were generated using the TNT coupled in vitro transcription/translation kit (Promega). The substrates were incubated with recombinant CED-3 (generated as described above) or caspase-3 (BioMol) for $90 \mathrm{~min}$ at $20^{\circ} \mathrm{C}(\mathrm{CED}-3)$ or $37^{\circ} \mathrm{C}$ (caspase-3).

\section{Acknowledgements}

We thank Trevor Lithgow and Lena Burri for their generous donation of the anti-GFP antibody and the p416-MET25-GFP ${ }^{\mathrm{S65T}}$ plasmid. We thank David Vaux for providing helpful suggestions about the manuscript and for stimulating discussions. This study was supported by the Australian Research Council and the National Health and Medical Research Council of Australia.

\section{References}

1. Sulston JE, Schierenberg E, White JG and Thomson JN (1983) The embryonic cell lineage of the nematode Caenorhabditis elegans. Dev. Biol. 100: 64-119

2. Yuan JY, Shaham S, Ledoux S, Ellis HM and Horvitz HR (1993) The C. elegans cell death gene ced 3 encodes a protein similar to mammalian interleukin-1beta-converting enzyme. Cell 75: 641-652

3. Xue D, Shaham S and Horvitz HR (1996) The Caenorhabditis elegans celldeath protein CED-3 is a cysteine protease with substrate specificities similar to those of the human CPP32 protease. Genes Dev. 10: 1073-1083

4. Salvesen GS (2002) Caspases and apoptosis. Essays Biochem. 38: 9-19

5. Sugimoto A, Friesen PD and Rothman JH (1994) Baculovirus p35 prevents developmentally programmed cell death and rescues a ced 9 mutant in the nematode Caenorhabditis elegans. EMBO J. 13: 2023-2028

6. Xue D and Horvitz HR (1995) Inhibition of the Caenorhabditis elegans celldeath protease CED-3 by a CED-3 cleavage site in baculovirus p35 protein. Nature 377: 248-251

7. Ellis HM and Horvitz HR (1986) Genetic control of programmed cell death in the nematode $C$. elegans. Cell 44: 817-829

8. Shaham S and Horvitz HR (1996) Developing Caenorhabditis elegans neurons may contain both cell-death protective and killer activities. Genes Dev. 10: 578-591

9. Wu D, Wallen $\mathrm{H}$, Inohara $\mathrm{N}$ and Nunez $\mathrm{G}$ (1997) Interaction and regulation of the Caenorhabditis elegans death protease CED-3 by CED-4 and CED-9. J. Biol. Chem. 272: 21449-21454

10. Chinnaiyan AM, Orourke K, Lane BR and Dixit VM (1997) Interaction of CED-4 with CED-3 and CED-9 - a molecular framework for cell death. Science 275: $1122-1126$

11. Chinnaiyan AM, Chaudhary D, O'Rourke K, Koonin EV and Dixit VM (1997) Role of CED-4 in the activation of CED-3. Nature 388: 728-729

12. Irmler M, Hofmann K, Vaux D and Tschopp J (1997) Direct physical interaction between the Caenorhabditis elegans death proteins CED-3 and CED-4. FEBS. Lett. 406: 189-190

13. Yang X, Chang HY and Baltimore D (1998) Essential role of CED-4 oligomerization in CED-3 activation and apoptosis. Science 281: 1355-1357

14. Hengartner MO, Ellis RE and Horvitz HR (1992) Caenorhabditis elegans gene ced-9 protects cells from programmed cell death. Nature 356: 494-499

15. Hengartner MO and Horvitz HR (1994) C. elegans cell survival gene ced-9 encodes a functional homolog of the mammalian proto-oncogene bcl-2. Cell 76: $665-676$

16. Vaux DL, Weissman IL and Kim SK (1992) Prevention of programmed cell death in Caenorhabditis elegans by human Bcl-2. Science 258: 1955-1957

17. Wu DY, Wallen HD and Nunez G (1997) Interaction and regulation of subcellular localization of CED-4 by CED-9. Science 275: 1126-1129

18. Spector MS, Desnoyers S, Hoeppner DJ and Hengartner MO (1997) Interaction between the $C$. elegans cell-death regulators CED-9 and CED-4. Nature 385: 653-656

19. Xue D and Horvitz HR (1997) Caenorhabditis elegans CED-9 protein is a bifunctional cell-death inhibitor. Nature 390: 305-308

20. Hawkins CJ, Wang SL and Hay BA (1999) A cloning method to identify caspases and their regulators in yeast: identification of Drosophila IAP1 as an inhibitor of the Drosophila caspase DCP-1. Proc. Natl. Acad. Sci. USA 96: 2885-2890

21. Kang J, Schaber M, Srinivasula S, Alnemri E, Litwack G, Hall D and Bjornsti M (1999) Cascades of mammalian caspase activation in the yeast Saccharomyces cerevisiae. J. Biol. Chem. 274: 3189-3198

22. Hawkins CJ, Yoo SJ, Petersen EP, Wang SL, Vernooy SY and Hay BA (2000) The Drosophila caspase DRONC cleaves following glutamate or aspartate and is regulated by DIAP1, HID, and GRIM. J. Biol. Chem. 275: 27084-27093

23. Hawkins CJ, Wang SL and Hay BA (2000) Monitoring activity of caspases and their regulators in yeast Saccharomyces cerevisiae. Methods Enzymol. 322: 162-174

24. Hawkins CJ, Silke J, Verhagen AM, Foster R, Ekert PG and Ashley DM (2001) Analysis of candidate antagonists of IAP-mediated caspase inhibition using yeast reconstituted with the mammalian Apaf-1-activated apoptosis mechanism. Apoptosis 6: 331-338 
25. Woo JS, Jung JS, Ha NC, Shin J, Kim KH, Lee W and Oh BH (2003) Unique structural features of a BCL-2 family protein CED-9 and biophysical characterization of CED-9/EGL-1 interactions. Cell Death Differ. 10: $1310-1319$

26. Shibata M, Kanamori S, Ohsawa Y, Watanabe T, Yayoi Y, Miura M, Kominami $\mathrm{E}$ and Uchiyama $Y$ (2001) Prevention of apoptosis of mammalian cells by the CED-3-cleaved form of CED-9. Arch. Histol. Cytol. 64: 17-28
27. Sikorski R and Hieter $P$ (1989) A system of shuttle vectors and yeast host strains designed for efficient manipulation of DNA in Saccharomyces cerevisiae. Genetics 122: 19-27

28. Wang SL, Hawkins CJ, Yoo SJ, Muller HA and Hay BA (1999) The Drosophila caspase inhibitor DIAP1 is essential for cell survival and is negatively regulated by REAPER, HID and GRIM, which disrupt DIAP1-caspase interactions. Cell 98: 453-463 